slowly evolved--these satellite systems being mainly attached be it noted to the more distant planetswhile the whole aggregation with its subsidiary bodies is gradually smoothed out by the frictional interactions of the mutual attractions of its parts into the now permanent solar system as a whole. The arresting difficulty in the Laplacian scheme, which arises from a large proportion of the angular momentum of the solar system which belongs to the larger planets, would thus be evaded in perhaps a very natural manner.

In any case, it is plausible speculation superposed on factual description that gives interest.to domains of abstract science.

Holywood,

Northern Ireland. Jan. 3.

\section{Rheology of Plastic Materials}

WE have been particularly interested in the letter from Dr. Scott-Blair and Miss Coppen on the com. pression of cylinders of soft materials, published in Nature of December 28, p. 840, as the treatment of compression test results by those workers appears to us to be of very wide application.

Considerable research has been carried out in our laboratories on the rheology of asphalts and bitumens, and in particular we have been working for some time on the extension and recovery of asphalt strips. These specimens, normally $30 \mathrm{~cm} . \times 2.5 \mathrm{~cm} . \times$ varying thicknesses ranging from $1.5 \mathrm{~mm}$. to $6.0 \mathrm{~mm}$., contain varying proportions of soluble bitumen ranging from about 14 to 80 per cent in conjunction with different fine mineral powders and sands.

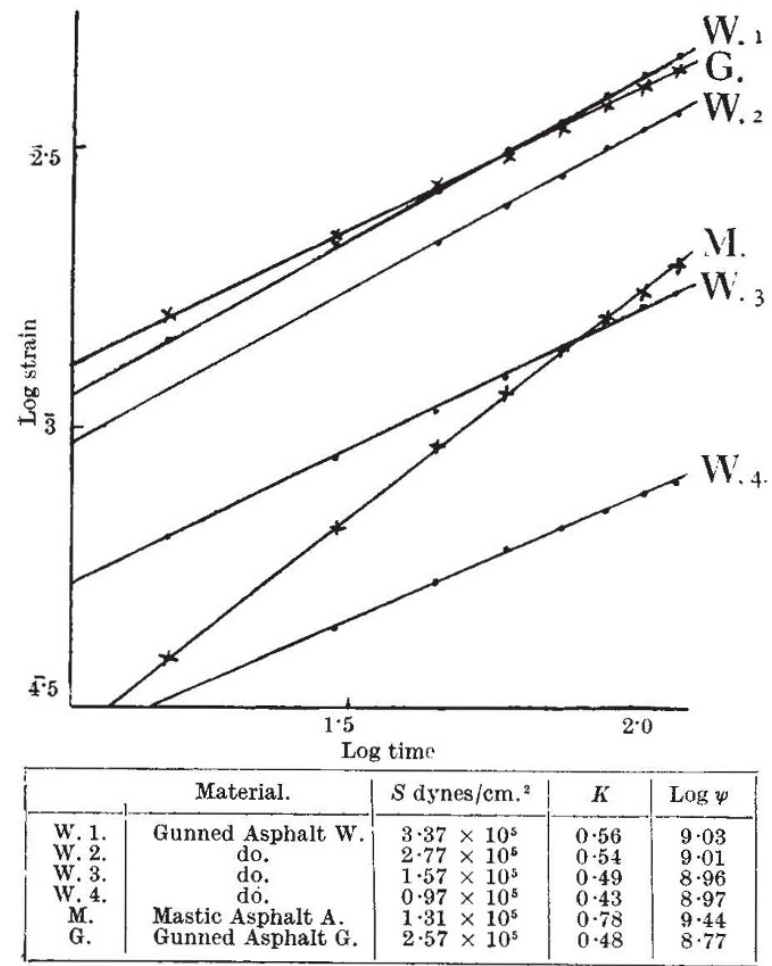

If the extension (and recovery) is plotted against time, curves are obtained which indicate that there is little or no immediate elastic extension on applying the load, or recovery on removing it, but the extension portion of the curve may be regarded as an elastic fore-effect on which is 'superimposed' an approximately linear viscous flow effect.

Similarly, the recovery portion of the curve is due to an elastic after-effect and is exponential in form. The most interesting point, however, is that if the results are treated according to the Scott-Blair procedure, and $\log$ strain plotted against log time, straight-line curves are obtained, and the equation $\psi=S \sigma^{4} t^{k}$ (where $S$ is the shearing stress, $\sigma$ is the strain, and $t$ is the time) is found to hold for these extension experiments just as well as for ScottBlair's compression work. Moreover, our work to date indicates that both $\psi$ and $k$ are substantially independent of $S$ for our materials.

A few typical results are given in the accompanying graph and table. The shearing stress was taken as one third of the tensile stress. Further work is being carried out, and full details will be published elsewhere.

D. C. BRoome.

L. Bilmes.

Limmer and Trinidad Lake Asphalt Co., Itd., Trinidad Wharf, Carnwath Road, I.ondon, S.W.6. Jan. 14.

\section{Prevention of Stem-Break, Browning and Seedling Blight in the Flax Crop}

Further to the reference ${ }^{1}$ made to the prevention of seed-borne diseases of flax by seed treatment, the completion of experimental work for 1940 has given the following results. Although the season was unsuitable for the spread of Colletotrichum Lini in the crop, seedling blight occurred quite commonly in brairds grown from infected seed. It was almost completely eliminated by seed treatment with $R D$. 7846 (Imperial Chemical Industries, Ltd.), used at $5 \mathrm{oz}$. per bushel $(56 \mathrm{lb}$.) of seed and by the short-wet method of seed treatment using Ceresan $U .564$ (Bayer Products, Ltd.) as the fungicide. Proprietary organo-mercurial dusts of proved efficiency against Helminthosporium disease of oats exercised a very good measure of control when applied to the seed at the rate of $10 \mathrm{oz}$. per bushel of seed. These results were obtained from a series of thirteen experimental centres scattered throughout the country and using samples of seed with percentage infections with C. Lini varying between $18 \cdot 2$ and $35 \cdot 7$.

A very promising measure of control of stem-break and browning (Polyspora Lini) was also obtained by employing the same methods of seed treatment. For this work seed samples with percentage infections of $P$. Lini varying from $2 \cdot 8$ to $23 \cdot 7$ were used at five experimental centres. The seedling and stem-break phases of the disease were largely eliminated by treatment, while the onset of the browning phase was longer delayed in crops grown from treated seed than in the controls.

Scutching tests were made on the crops grown in an exhaustive series of replicated and randomized plots at the Agricultural Research Institute, Hillsborough. For the stem-break and browning trials a seed sample carrying $23 \cdot 7$ per cent infected seed was used, and here significant increases in fibre yield ranging from 30 to 60 per cent were obtained from crops where the seed had been submitted to one or other of the aforementioned treatments. In the case of the series of seedling blight trials the differences were not so marked; the season was not suitable for the spread of the disease beyond the seedling 